\title{
ANÁLISE DA INFLUÊNCIA DO ACONDICIONAMENTO DIFERENCIADO DE LÂMINAS PARA COLPOCITOLOGIA NO RESULTADO LABORATORIAL
}

\author{
Camila Félix Américo ${ }^{1}$, Ana Carolina Maria Araújo Chagas², Emeline Moura Lopes³ ${ }^{3}$ Levânia Maria Benevides \\ Dias $^{4}$, Thaís Marques Lima ${ }^{5}$, Escolástica Rejane Ferreira Moura ${ }^{6}$, Ana Karina Bezerra Pinheiro
}

\footnotetext{
${ }^{1}$ Mestranda em Enfermagem pela Universidade Federal do Ceará (UFCE). Bolsista do Programa REUNI de Orientação e Operacionalização da Pós-Graduação articulada à Graduação. Ceará, Brasil. E-mail: camilaamerico@yahoo.com.br

2 Acadêmica de Enfermagem da UFCE. Bolsista do Programa de Educação Tutorial. Ceará, Brasil. E-mail: aninhaaraujoc@ hotmail.com

${ }^{3}$ Mestre em Enfermagem pela UFCE. Ceará, Brasil. E-mail: emelinepet@yahoo.com.br

${ }^{4}$ Enfermeira pela UFCE. Ceará, Brasil. E-mail: levaniadias@hotmail.com

${ }^{5}$ Enfermeira pela UFCE. Ceará, Brasil.. E-mail: thaixinha@yahoo.com.br

${ }^{6}$ Doutora em Enfermagem. Professor Adjunto da UFCE. Pesquisadora CNPq. Ceará, Brasil. E-mail: escolpaz@yahoo.com.br

${ }^{7}$ Doutora em Enfermagem. Professor Adjunto da UFCE. Ceará, Brasil. E-mail: anakarinaufc@hotmail.com
}

\begin{abstract}
RESUMO: Objetivou-se verificar a influência das formas de acondicionamento de lâminas de colpocitologia nos resultados dos laudos laboratoriais concernentes a Epitélios Representativos da Amostra, Alterações Celulares Benignas e atipias celulares. Estudo descritivo, quantitativo, realizado entre abril e junho de 2008. Participaram 72 mulheres que realizaram exame preventivo do câncer de colo uterino, em um Centro de Parto Natural de Fortaleza-CE. De cada participante foram coletados dois esfregaços de espécime cérvico-vaginal: um foi acondicionado junto ao de outras usuárias (caso), e outro isoladamente (controle), atendendo aos padrões técnicos. Seguiu-se o critério de "cegagem" da leitura das lâminas. Os resultados das duas lâminas foram comparados verificando discordâncias nos diferentes armazenamentos. Houve discordância de 58,3\% em relação aos Epitélios Representativos da Amostra e $48,2 \%$ com relação às Alterações Celulares Benignas. Os resultados sugerem novos estudos sobre formas de acondicionamento, controle da intrasubjetividade do técnico responsável pela leitura e ordem de coleta das lâminas caso e controle.
\end{abstract}

DESCRITORES: Prevenção de câncer de colo uterino. Esfregaço vaginal. Enfermagem em saúde pública.

\section{ANALYSIS OF INFLUENCE OF PACKAGING DIFFERENTIATED OF BLADES OF COLPOCITOLOGIA THE RESULT OF LABORATORY'S RESULT}

\begin{abstract}
The aim of this study was to verify the influence of packing types of cytology slides in laboratory report results pertaining to Sample Epithelia Representatives, Benign Cellular Alterations, and cellular atypia. This is a descriptive and quantitative study conducted between April and June of 2008. The participants were 72 women who underwent cervical cancer preventive examinations in a Center for Natural Childbirth, Fortaleza, Ceará, Brazil. From each participant we collected two cervical smears of vaginal specimen: one was put next to other users (case), and the other alone (control), given the technical standards. This was followed by the criterion of blind control in reading the slides. The results of the two blades were compared by checking inconsistencies in the various packing realities. There was a $58.3 \%$ discrepancy compared to epithelia representative samples and $48.2 \%$ compared to benign cellular changes. The results suggest further studies are needed regarding packaging, control of the intra-subjectivity of the technician responsible for reading, and the sequence for collecting case and control slides.
\end{abstract}

DESCRIPTORS: Cervix neoplasms prevention. Vaginal smears. Public health nursing

\section{ANÁLISIS DE LA INFLUENCIA DEL ALMACENAMIENTO DIFERENCIAL DE HOJAS DE COLPOCITOLOGÍA EN EL RESULTADO DE LABORATORIO}

RESUMEN: En este estudio se evaluó la influencia de los tipos de embalaje de hojas de la citología en los resultados de los informes de laboratorio relativos al epitelio de muestra representativa, los cambios celulares benignos y atipia celular. Es un estudio descriptivo, cuantitativo, realizado entre abril y junio de 2008. Las participantes fueron 72 mujeres que se sometieron a exámenes preventivos para el cáncer cervical en un Centro de Parto Natural, en la ciudad de Fortaleza, Ceará, Brasil. De cada participante se recogieron dos muestras de frotis cervical vaginal: uno fue puesto al lado del de otras usuarias (caso), y uno solo (control), teniendo en cuenta las normas técnicas. Se realizó el criterio de "cegagem" de la lectura de las hojas. Los resultados de las dos hojas fueron comparados y fue visto incompatibilidades en los diferentes almacenamientos. Un desacuerdo fue de 58,3\% en comparación con el epitelio de muestra representativa, y $48,2 \%$ en comparación con cambios celulares benignos. Los resultados sugieren nuevos estudios sobre las formas de almacenamiento, control de la intrasubjetividad del técnico responsable de leer y ordenar la recolección de las hojas de casos y control.

DESCRIPTORES: Prevención de cáncer de cuello uterino. Frotis vaginal. Enfermería en salud pública. 


\section{INTRODUÇÃO}

As doenças crônico-degenerativas são causas de elevada morbidade e mortalidade mundial e, dentre estas, o câncer tem respondido por altas taxas de óbitos. No que se refere à população feminina, o Câncer do Colo do Útero (CCU) é de grande relevância epidemiológica.

De acordo com dados do Instituto Nacional do Câncer (INCA), a estimativa da incidência dessa neoplasia no país, para 2010, é de 18.430 casos, com risco esperado de 18 a cada 100 mil mulheres. ${ }^{1}$

Sabe-se, contudo, que o CCU se configura como um dos tipos de câncer com maior possibilidade de detecção precoce, por meio de exame como a colpocitologia oncótica, pontuando a importância da realização deste exame de forma rotineira. $^{2}$

As técnicas de detecção precoce são caracterizadas pela colpocitologia oncológica ou teste de Papanicolaou, colposcopia, cervicografia, e os testes de detecção do DNA do Vírus Papiloma Humano (HPV). ${ }^{3}$

O exame de Papanicolaou, citologia oncótica ou Pap test, consiste na obtenção de amostras celulares da ectocérvice e endocérvice, objetivando detectar possíveis alterações celulares e lesões pré-cancerosas. Todavia, apesar da larga adesão da colpocitologia oncólogica como método de rastreamento, muitos são os fatores que direta ou indiretamente interferem no seu resultado, a saber: modo de utilização da escovinha endocervical, registro de dados clínicos importantes e interpretação laboratorial. ${ }^{4}$

Todas as etapas do exame, desde o acolhimento da usuária até a coleta do material celular, devem ser feitas considerando padrões de qualidade, para garantir a confiabilidade da amostra e assegurar um resultado confiável.

A utilização de diferentes técnicas na preparação das lâminas, bem como distintos instrumentos para a coleta do esfregaço, podem gerar fatores de confusão, levando a vieses que repercutirão em sua sensibilidade e especificidade. ${ }^{5}$

O controle interno da qualidade na colpocitologia oncológica objetiva apontar exames falsonegativos e assim definir a necessidade de revisão e re-exame, possibilitando alcançar resultados confiáveis. ${ }^{6}$

Da coleta do exame até a entrega do resultado à usuária, há um longo percurso, a envolver muitos profissionais e muitas técnicas. Portanto, a coleta do esfregaço, fixação, coloração e manipulação laboratorial, bem como a competência do examinador podem influenciar no resultado do laudo final, e consequentemente, a conduta a ser tomada, a qual é baseada na conclusão do exame. ${ }^{7}$

Tendo em vista as afirmações levantadas e considerando que o exame de colpocitologia oncótica é predominantemente manual, todas as suas etapas devem ser criteriosamente analisadas. Desse modo, surge uma indagação relacionada ao acondicionamento dos esfregaços: diferentes formas de acondicionamento das lâminas poderiam interferir no laudo citológico?

Diante do exposto, objetivou-se verificar a influência das formas de acondicionamento de lâminas para colpocitologia oncológica nos laudos laboratoriais concernentes a Epitélios Representativos da Amostra (ERA), Alterações Celulares Benignas (ACB) e presença de atipias celulares.

\section{METODOLOGIA}

O estudo caracterizou-se como uma pesquisa descritiva comparativa, ${ }^{8}$ com abordagem quantitativa realizado em um Centro de Parto Natural $(\mathrm{CPN})$, de Fortaleza-CE, no período de abril a junho de 2008. A pesquisa descritiva apresenta informações e dados, indicando possíveis regularidades ou irregularidades e situando de acordo com as circunstâncias. Já a abordagem quantitativa se apóia na apresentação de dados numéricos e estatísticos, sem estar, necessariamente, vinculada a hipóteses. ${ }^{9}$

Participaram 72 mulheres atendidas no referido local, selecionadas pelos critérios de ter maioridade legal e ter comparecido ao serviço durante o período da coleta de dados. Foram excluídas as mulheres com impossibilidade de visualização do colo uterino pela presença de hímen, as histerectomizadas e aquelas sem condições mentais para responder aos questionamentos e responsabilizarse legalmente. Portanto, a amostra foi constituída por todas as mulheres atendidas no período, sendo captadas para o estudo aquelas que se enquadravam nos critérios de inclusão.

A coleta dos dados ocorreu durante a consulta ginecológica (prevenção do câncer de colo uterino) de rotina de realizada por enfermeiros, momento em que foram pesquisados os dados sociodemográficos, por meio de entrevista estruturada, e em que foi realizada a coleta citológica, 
que seguiu os padrões técnicos estabelecidos para uma técnica adequada. ${ }^{10}$ Em uma segunda etapa, foi realizada leitura dos laudos citopatológicos das respectivas lâminas, comparando-se o laudo da lâmina acondicionada isoladamente com o laudo da que foi acondicionada junto às outras lâminas.

O exame de colpocitologia oncótica consiste na coleta de material proveniente da ecto e endocérvice. $\mathrm{O}$ material da ectocérvice deve ser coletado com espátula de Ayre, já a amostra da endocérvice é feita com escova endocervical. Após a coleta, o esfregaço vaginal é disposto em uma lâmina previamente identificada e submerso em solução de álcool absoluto (96\%). ${ }^{10}$

Para coleta dos casos e controles, procederam-se as seguintes etapas:

- Foram coletados, concomitantemente, dois esfregaços de espécime cérvico-vaginal de cada mulher pesquisada;

- O primeiro foi armazenado no portalâminas em conjunto com outras duas amostras (de duas outras mulheres), seguindo o protocolo de realização do exame de colpocitologia oncótica utilizado na atenção básica (amostras A - caso); ${ }^{10}$

- O segundo foi codificado e armazenado isoladamente, a fim de ter os laudos comparados (amostras B - controle).

Para cada mulher foi utilizado um código estabelecido pelas pesquisadoras, de modo a identificar os laudos a posteriori, e este ficou no desconhecimento da técnica de laboratório responsável pela leitura das lâminas ("cegagem"). A mesma técnica de laboratório realizou a leitura das lâminas dos dois grupos.

A coleta foi realizada por dois profissionais (enfermeiros) envolvidos no estudo e com orientação prévia acerca do método de identificação e armazenamento de cada lâmina.

Todos os laudos foram emitidos com base no Sistema Bethesda, fornecendo informações concernentes à adequabilidade do material coletado, ERA, ACB reativas ou reparativas, microbiologia e parecer para alterações compatíveis ou não com neoplasia. Todavia, neste estudo foram comparados resultados referentes a ERA, ACB e presença de atipias celulares escamosas - ASCUS e glandulares - ASGUS.

Para organização e análise dos dados, foi utilizado o software Statistical Package for Social Sciences for Personal Computer (SPSS-PC), versão 14.0. Foram analisadas as frequências absolutas e relativas, bem como foi feito o cruzamento de dados referentes às amostras caso e controle.

O projeto de pesquisa foi submetido e aprovado pelo Comitê de Ética em Pesquisa da Universidade Federal do Ceará, segundo o Parecer $\mathrm{n}^{\circ} 29 / 08$. Foram seguidas as recomendações da Resolução no 196/96, do Conselho Nacional de Saúde, que trata de pesquisas envolvendo seres humanos, sendo respeitado o livre consentimento, a beneficência e não maleficência. ${ }^{11}$ Cada participante, após informada sobre o processo da pesquisa e seus objetivos, assinou o Termo de Consentimento Livre e Esclarecido.

\section{RESULTADOS}

Das condições sociodemográficas das participantes, $42(55,5 \%)$ tinham idade inferior a 40 anos, sendo que $20(28,0 \%)$ estavam na faixa etária entre 18 e 30 anos e 22 (30,5\%) entre 31 e 40 anos; 44 (61,1\%) haviam cursado o ensino fundamental; 39 (54,2\%) eram casadas ou estavam em união consensual.

No laudo citopatológico do colo do útero, as características do material analisado foram categorizadas de acordo com a adequabilidade da amostra, representatividade do epitélio, ACB, microbiologia e parecer quanto à presença de atipias celulares. O material biológico de todas as mulheres em estudo, tanto dos casos quanto dos controles, foi considerado satisfatório, não havendo, portanto, a necessidade da repetição imediata de alguma amostra. Houve concordância em todos os laudos, tanto dos casos quanto dos controles.

Verificada a adequabilidade das amostras A e B, seguiu-se com a avaliação da representatividade do epitélio (Figura 1).

Os epitélios encontrados nas amostras A (caso) e B (controle) diversificaram-se entre escamoso, escamoso/glandular e escamoso/glandular/metaplásico. 


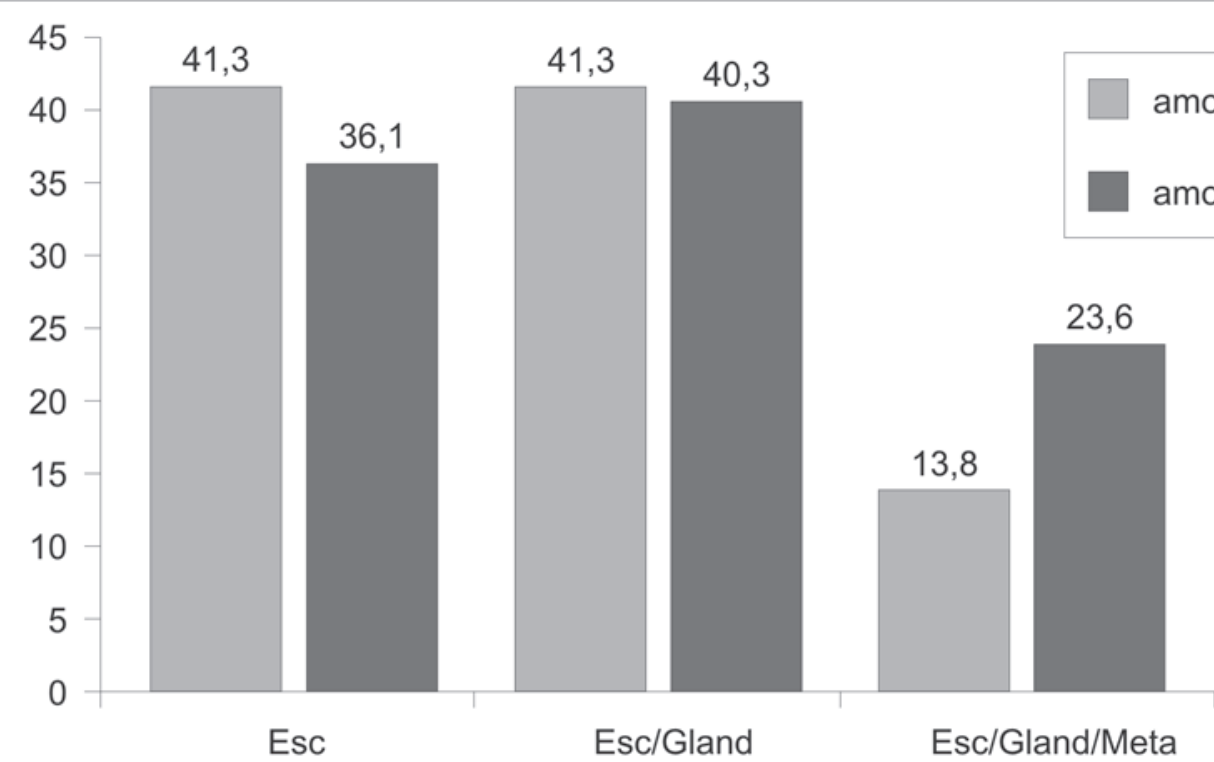

Figura 1 - Distribuição percentual dos epitélios representativos nas amostras dos casos e controles. Centro de Parto Natural, Fortaleza-CE, 2008

No que diz respeito à representatividade epitelial da amostra A, 43,1\% dos esfregaços foram escamosos, $41,3 \%$, escamoso/glandular e $13,8 \%$, escamoso/glandular/metaplásico. $\mathrm{Na}$ amostra B, o epitélio escamoso foi observado em $36,1 \%$; o escamoso/glandular em $40,3 \%$ e o escamoso/ glandular/metaplásico, em 23,6\%. As amostras celulares que foram acondicionadas conjuntamente (amostra A - caso) apresentaram uma maior taxa de epitélio escamoso e escamoso/glandular $(43,1 \%)$. Já nos esfregaços acondicionados em um único porta-lâmina (amostra B- controle), a maior representatividade foi para o epitélio escamoso/ glandular (40,3\%) (Tabela 1).

Tabela 1 - Resultados dos laudos citopatológicos dos casos e controles segundo epitélios representados. Centro de Parto Natural, Fortaleza-CE, 2008

\begin{tabular}{lccc}
\hline \multirow{2}{*}{ Amostra A - casos } & \multicolumn{3}{c}{ Amostra B - controles } \\
\cline { 2 - 4 } & Escamoso & Esc/gland* & Esc/gland/metaplásico \\
\hline Escamoso & 12 & 11 & 8 \\
Esc/gland & 12 & 14 & 5 \\
Esc/gland/metaplásico & 2 & 4 & 4 \\
\hline
\end{tabular}

*Esc/gland - Escamoso/glandular

Dos 72 pares de exames analisados, o percentual de concordância foi de $30(41,7 \%)$ e discordância em 42 (58,3\%). Sendo assim, muitas mulheres (42) obtiveram laudos diferentes segundo a representatividade epitelial. O maior percentual de concordância ocorreu na classificação epitélio escamoso/glandular. Isso quer dizer que algumas mulheres poderiam estar apresentando uma metaplasia sem detecção laboratorial.
Deve-se, contudo, considerar a subjetividade que há na análise das amostras, o que pode gerar variabilidade diagnóstica intra e interobservador. ${ }^{12}$ Os profissionais responsáveis pela realização do exame e, portanto, envolvidos na coleta, precisam atentar a todos os aspectos técnicos necessários para um bom desempenho na realização do exame, assim como os citotécnicos e citopatologistas, que devem sempre envolver-se 
em programas que garantam a qualidade do exame de colpocitologia oncótica. Vê-se, portanto, a necessidade de uma auto-avaliação contínua destes profissionais que exercem um papel fundamental no resultado final do exame. ${ }^{7}$

A presença de células metaplásicas se constitui em um fator ligado a menor índice de resultados falso-negativos. A presença destas células, inclusive, é considerada como um parâmetro de bom desempenho na realização do exame citopatológico. ${ }^{13-14}$

No que reporta às reações celulares benignas, a Figura 2 demonstra os achados de acordo com o resultado dos laudos citopatológicos do colo do útero dos casos e controles.

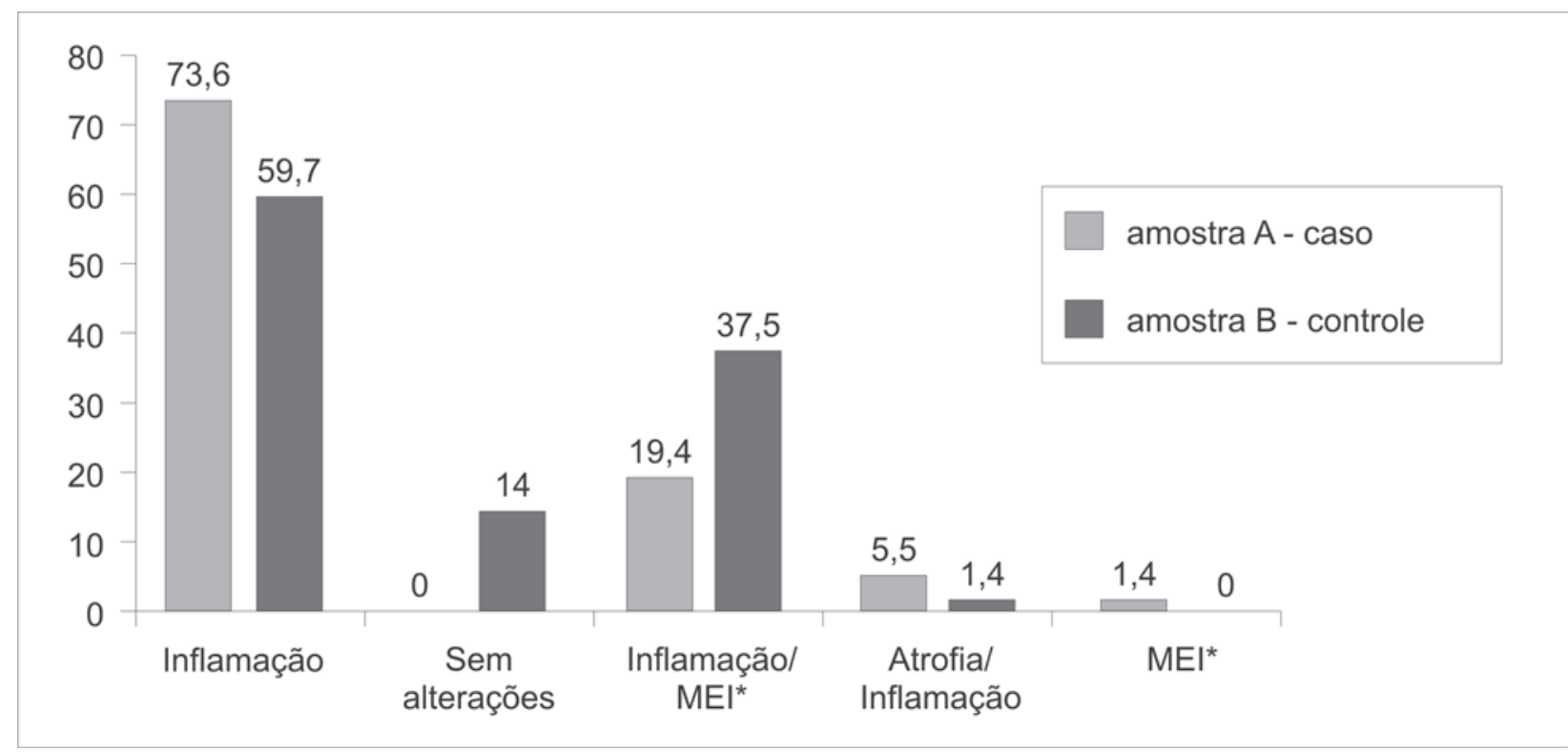

* MEI- Metaplasia Escamosa Imatura

Figura 2 - Distribuição percentual das alterações celulares benignas nas amostras dos casos e controles. Centro de Parto Natural, Fortaleza-CE, 2008

Dentre as alterações celulares benignas, ativas ou reparativas, pode-se encontrar classificações como: dentro dos limites da normalidade no material examinado, Inflamação, Metaplasia Escamosa Imatura (MEI), Reparação, Atrofia com inflamação ou Radiação. A discriminação "no material examinado" ao exame dito como "normal" objetiva deixar explícito o aspecto observado no momento do exame. ${ }^{15}$ Nesse estudo encontrou-se variação entre Exame normal, Inflamação, MEI e Atrofia.

A inflamação, isoladamente, foi a mais importante alteração celular observada, tanto na amostra A com 73,6\%, quanto na B com 59,7\%. $A$ reação encontrada com menor frequência na amostra A foi MEI, com 1,4\%; já na amostra B, foi Atrofia/Inflamação com 1,4\% dos casos em análise.

Estudo realizado entre 2004 e 2005, com 1.780 mulheres atendidas em ambulatório de ginecolo- gia preventiva no estado do Rio de Janeiro, ratifica a maior prevalência da inflamação encontrada na presente investigação, ao demonstrar que 90,2\% das mulheres pesquisadas apresentaram alterações inflamatórias em vagina e/ou cérvice. ${ }^{16}$

Quanto à caracterização dos epitélios representados na amostra, a designação "imatura" anexada à metaplasia escamosa objetivou explicitar que esta alteração é considerada como do tipo inflamatória, sendo que o epitélio nesta fase está susceptível à ação de agentes microbianos, em especial o HPV.

Todavia, a conduta diante deste achado segue a rotina de rastreamento, a saber: retorno anual para nova avaliação ou após três anos, caso tenham sido realizados dois exames anteriores com resultados negativo. ${ }^{13}$

Ao associar os achados entre os dois grupos, verificaram-se os laudos apresentados na Tabela 2. 
Tabela 2 - Resultados dos laudos citopatológicos dos casos e controles conforme alterações celulares benignas. Centro de Parto Natural, Fortaleza-CE, 2008

\begin{tabular}{lcccc}
\hline \multirow{2}{*}{ Amostra A - casos } & \multicolumn{4}{c}{ Amostra B - controles } \\
\cline { 2 - 5 } & Inflamação & Normal & Inflamação/MEl* & Atrofia/Inflamação \\
\hline Inflamação & 32 & 1 & 20 & - \\
MEI & 1 & - & - & - \\
Inflamação/MEI & 9 & - & 5 & - \\
Atrofia/Inflamação & 1 & - & 2 & 1 \\
\hline
\end{tabular}

* MEI - Metaplasia Escamosa Imatura

No que diz respeito à MEI, com ou sem inflamação, observa-se que, enquanto nos esfregaços que foram acondicionados conjuntamente obteve-se uma frequência de 15 (20,8\%), nos esfregaços dispostos em um único porta-lâmina essa frequência atingiu $27(37,5 \%)$, sendo esta uma diferença considerável.

Destarte, é possível que o citopatologista tenha interpretado algumas lâminas, ora com a designação "inflamação" ora com "metaplasia escamosa imatura", com parâmetros muito estreitos de análise, visto que, na amostra $\mathrm{A}$, a maior parte das lâminas, $53(76,6 \%)$, foi discriminada na categoria inflamatória em detrimento da MEI. Já na amostra B, houve uma distribuição mais equilibrada entre a categoria "inflamação", com $43(59,7 \%)$ e esta associada à MEI, com $27(37,5 \%)$. As duas classificações são do tipo inflamatório, e essa alternância de classificação não gera grande impacto na conduta clínica.

É pertinente ressaltar também que, enquanto na amostra $B$ houve um $(1,4 \%)$ caso com o exame de acordo com os padrões da normalidade, o exame correspondente, na amostra A, indicou inflamação, o que pode gerar conduta diferenciada e repercussão negativa no seguimento desta mulher.

A inflamação é determinada, frequentemente, pela ação de agentes físicos ou químicos que geram reações nas células que a eles se expõem. A metaplasia também é uma alteração do tipo inflamatório. Contudo, o epitélio, nesta fase, está mais vulnerável a microorganismos maléficos, dentre eles o HPV. A conduta preconizada nestes casos é seguir rotina de rastreamento citológico. ${ }^{13}$

Porém, havendo queixa clínica de secreção anormal, a cliente deverá submeter-se a exame ginecológico. Os achados rotineiros são ectopias, vaginites, vaginoses e cervicites. Diante destas alterações, deve-se seguir ao tratamento segundo recomendação específica. ${ }^{10}$
Quanto ao percentual de concordância entre os laudos citológicos, observou-se que em 38 $(52,8 \%)$ os resultados concordaram. Entretanto, considerando o percentual de discordância, obtevese $47,2 \%$, ou seja, 34 mulheres tiveram seus exames com resultados diferentes ou discordantes.

Vê-se que até a obtenção do laudo citológico do colo do útero há um longo processo manual envolvido: a coleta do esfregaço, a fixação, a coloração e manipulação laboratorial como um todo; além de outros fatores como experiência do examinador. ${ }^{7}$

Por conta dessa diversidade de etapas, com diferentes pessoas envolvidas, algumas falhas podem vir a ocorrer. Por isso, se torna indispensável o aprimoramento técnico dos profissionais envolvidos na realização do exame da colpocitologia oncótica, e não só isso: todos os fatores que podem influenciar, de algum modo, a interpretação do exame, como a sobrecarga de trabalho, por exemplo, devem ser investigados.

Procedeu-se também a análise dos exames conforme a presença ou não de células atípicas de significados indeterminados (Tabela 3).

Tabela 3 - Distribuição dos resultados dos laudos citopatológicos dos casos e controles conforme presença de atipias celulares. Centro de Parto Natural (CPN), Fortaleza-CE, 2008.

\begin{tabular}{lcc}
\hline \multirow{2}{*}{ Amostra A - casos } & \multicolumn{2}{c}{ Amostra B - controles } \\
\cline { 2 - 3 } & $\begin{array}{c}\text { Negativo para } \\
\text { neoplasia }\end{array}$ & ASCUS \\
\hline Negativo para neoplasia & 69 & 3 \\
\hline
\end{tabular}

Verificou-se que, dos 72 pares de exames obtidos, 69 (96,0\%) foram concordantes entre si e três $(4,0 \%)$ foram discordantes. Assim sendo, três 
(4\%) mulheres tiveram seus exames com diferentes laudos, o que, neste caso, implica também em diferentes condutas. Posto isso, pode-se constatar que houve um percentual elevado de concordância entre os laudos.

No laudo com parecer negativo para neoplasia, deve-se aconselhar a mulher a retornar no ano subsequente ou após três anos, caso tenha dois exames prévios anuais negativos. Todavia, nos laudos com atipias escamosas de significado indeterminado, a conduta preconizada seria marcar um retorno após seis meses para uma nova coleta. Foi interessante observar também que as atipias só foram interpretadas como tais nas lâminas armazenadas isoladamente.

Diante da presença de células escamosas atípicas de significado indeterminado, possivelmente não neoplásicas, é aconselhável que se repita a colpocitologia oncológica em seis meses, na unidade básica de saúde. Caso haja dois exames citopatológicos semestrais subsequentes negativos, a cliente retornará para rotina de rastreamento citológico. ${ }^{13}$

Ao se analisar o percentual de concordância dos exames, no que concerne à presença de atipias celulares diante de diferentes formas de acondicionamento, viu-se que, apesar de ter-se obtido um baixo percentual de discordância (4\%), presume-se que possa ter ocorrido resultados falso-negativo na amostra A ou falso-positivo na amostra B.

No que diz respeito ao quantitativo de resultados falso-negativos, relata-se que há ligação quanto à qualidade de coleta, visto que a lesão pode não estar satisfatoriamente representada no esfregaço, assim como outros fatores que obscurecem o mesmo, como presença abundante de sangue e processo inflamatório aturado, comprometendo a análise. ${ }^{14}$

Em contrapartida, com relação à taxa de resultados falso-negativos ou falso-positivos, estudos mostram que fatores como preparações inadequadas dos esfregaços, ausência de controle de qualidade dos laboratórios de citopatologia, interpretação inadequada dos achados citológicos e seguimento inadequado das mulheres com esfregaços alterados são limitações importantes a serem consideradas e estudadas. ${ }^{17}$

Vê-se que são citados aspectos referentes tanto à técnica de coleta quanto à leitura da lâmina, quando se analisa erro de diagnóstico. Entretanto, neste estudo, a técnica de coleta foi realizada conforme recomendações do Ministério da Saúde, sendo seguidos todos os quesitos necessários para realização de uma coleta citológica adequada e satisfatória. Destarte, o presente estudo sugere que os diferentes resultados advieram de outros fatores que não a técnica de coleta e que, apesar de controlada a variável acondicionamento, a intrasubjetividade do técnico de laboratório não pode ser descartada.

Quanto ao acondicionamento, viu-se que este pode ter influenciado o laudo citológico, mas outro aspecto que também pode ter exercido alguma influência no resultado foi o fato de a lâmina controle ter sido sempre a segunda a ser coletada, estando-se, pois, teoricamente, diante de condições mais escassas para obtenção de um adequado esfregaço.

Além dessas, outras variáveis devem ser consideradas quando se depara com resultados divergentes ou não fidedignos: ausência de atenção e centralização, tempo insuficiente para avaliar o esfregaço, sobrecarga de trabalho e insuficiente experiência do profissional. ${ }^{12}$

Para minimizar a taxa de resultados não confiáveis, algumas estratégias são propostas e comprovadamente efetivas. A revisão rápida de $100 \%$ dos esfregaços é uma opção eficiente para reduzir a taxa de falsos negativos dos exames citopatológicos, principal revés do exame. Este método possibilita que se veja o desempenho individual, encontrando deficiências, diferenças ou dificuldades dos profissionais no que diz respeito à interpretação diagnóstica. ${ }^{18}$

Sabendo que o exame de colpocitologia oncótica é amplamente utilizado para o rastreamento de lesões precursoras do CCU e que se implementado de maneira efetiva pode reduzir significantemente os índices de morbidade e mortalidade por este tipo de neoplasia, existe necessidade de controle de qualidade nos programas de screening para o CCU, além de efetivo seguimento e tratamento dos casos detectados com alterações. ${ }^{19}$

\section{CONCLUSÃO}

Percentuais significativos de laudos divergentes relativos às amostras caso e controle de lâminas para exame de colpocitologia oncótica sugerem a realização de novos estudos a explorar o acondicionamento das lâminas, pois apesar de terse tomado o cuidado de designar a mesma técnica de laboratório para a leitura de todas as lâminas, tal zelo não retira a influência da intrasubjetividade de quem realiza a leitura. Acondicionamento ou subjetividade? A discordância entre os laudos precisa ser reduzida. 
Quanto ao acondicionamento, viu-se que este pode ter exercido alguma influência no laudo citológico do colo do útero, mas o fato de a lâmina "controle" ter sido sempre a segunda a ser preparada pode ter influenciado a qualidade do esfregaço. Estudos posteriores que tornem possível a alternância na ordem de preparação das lâminas, garantindo que 50,0\% de lâminas "caso" sejam primeiramente preparadas e 50,0\% de lâminas "controle" também sejam preparadas inicialmente irá diminuir variáveis que causem confusão na análise e inferência de resultados.

A realização deste trabalho firma a idéia de que o enfermeiro deve pautar sua assistência em princípios teóricos e mediante reflexão, demonstrando que as inquietações empíricas devem ser pesquisadas.

\section{REFERÊNCIAS}

1. Ministério da Saúde (BR). Programa Nacional de câncer do colo do útero e de mama - Viva Mulher [online]. 2010 [acesso 2010 Mai 08]. Disponível em: http:/ / www.inca.gov.br/conteudo_view.asp?id=140.

2. Beghini AB, Salimena, AMO, Melo MCSC, Souza, IEO. Adesão das acadêmicas de enfermagem à prevenção do câncer ginecológico: da teoria à prática. Texto Contexto Enferm. 2006 Out-Dez; 13(4):637-44.

3. Pinho AA, França-Júnior I. Prevenção do câncer de colo do útero: um modelo teórico para analisar o acesso e a utilização do teste de Papanicolaou. Rev Bras Saúde Matern Infant. 2003 Jan-Mar; 3(1):95-112.

4. Amaral RG, Ribeiro AA, Miranda FA, Tavares SBN, Souza NLA, Manrique EJC, et al. Fatores que podem comprometer a qualidade dos exames citopatológicos no rastreamento do câncer do colo do útero. RBAC. 2006 Jan-Mar; 38(1):3-6.

5. Hyppólito SB. O uso do ácido acético no diagnóstico precoce do câncer cérvico-uterino [tese]. Campinas (SP): Faculdade de Ciências Médicas. Universidade Estadual de Campinas; 2002.

6. Arcuri RA, Cunha KCF, Alves EC, Castro AA, Maciel RA, Rosmanino AC, et al. Controle interno da qualidade em citopatologia ginecológica: um estudo de 48. 355 casos. J Bras Patol Med Lab. 2002; 38(2):141-7.

7. Motta EV, Fonseca AM, Bagnoli VR, Ramos LO, Pinotti JA. Colpocitologia em ambulatório de ginecologia preventiva. Rev Assoc Med Bras. 2001 Dez; 47(4):302-10.
8. Mendes S, Pinotti JA, Fonseca M, Nisida ACT, Ruiz CA. Estudo comparativo de dois métodos de avaliação de risco para câncer de mama. Rev Ginecol Obstet. 2004 Jul-Set;15(3):129-35.

9. Rogrigues RM. Pesquisa acadêmica: como facilitar o processo de preparação de suas etapas. São Paulo (SP): Atlas; 2007.

10. Ministério da Saúde (BR). Controle dos cânceres do colo do útero e da mama. Brasília (DF): MS; 2006.

11. Ministério da Saúde (BR), Resolução No 196 de 10 de outubro de 1996: diretrizes e normas regulamentadoras de pesquisa envolvendo seres humanos. Brasília (DF): MS; 1996.

12. Tavares SBN, Amaral RG, Manrique EJC, Sousa NLA, Albuquerque ZBP, Zeferino LC. Controle da qualidade em citopatologia cervical: revisão de literatura. Rev Bras Cancerol. 2007 Jul-Set; 53(3):355-64.

13. Ministério da Saúde (BR). Nomenclatura brasileira para laudos cervicais e condutas preconizadas. Brasília (DF): MS; 2006.

14. Franco R. Fatores associados a resultados falsonegativos de exames citopatológicos do colo uterino [dissertação]. Campinas (SP): Faculdade de Ciências Médicas, Universidade Estadual de Campinas; 2006.

15. Derchain SFM, Longatto-Filho A, Syrjanen KJ. Neoplasia intra-epitelial cervical: diagnóstico e tratamento. Rev Bras Ginecol Obstet. 2005 Jul; 27(7):425-33.

16. Souza LG, Vianna ACC. Análise dos exames colpocitológicos de clientes atendidas pelo ambulatório de ginecologia preventiva do Hospital Geral de Bonsucesso-RJ, no período entre maio/2004 e abril/2005 [online]. 2005 1-16 [acesso 200815 jul]. Disponível em: http://www.castelobranco.br/ sistema/novoenfoque/files/05/03.pdf

17. Corte LMD, Gonsalves JC, Silva CS, Dutra MF, Rocha DB, Utizg CB, et al. Análise da Concordância Interobservadores em exames de papanicolaou. [online] 2007 [acesso 2008 Jul 15]. Disponível em: http://www.newslab.com.br/newslab/pdf/ artigos80/art03/art03.pdf.

18. Amaral RG, Santos SHR, Catharino JMR, Silva LCB, Westin MCA, Cotta AC, et al. Revisão rápida de esfregaços cervicais como método de garantia interna de qualidade. J Bras Patol Med Lab. 2003 Abr-Jun; 39(2):151-5.

19. Rama C, Martins CR, Derchain S, Longatto-Filho A, Gontijo R, Sarian L, et al. Rastreamento anterior para câncer de colo uterino em mulheres com alterações citológicas ou histológicas. Rev Saúde Pub. 2008 Jun; 42(3):411-9. 